\title{
DEXA: a practical and accurate tool to demonstrate total and regional bone loss, lean tissue loss and fat mass gain in paraplegia
}

\author{
LM Jones $^{1}$, A Goulding ${ }^{2}$ and DF Gerrard ${ }^{1}$ \\ ${ }^{1}$ The School of Physical Education and the ${ }^{2}$ Department of Medicine, University of Otago, Dunedin, New Zealand
}

\begin{abstract}
Persons with spinal cord injury lose lean tissue mass and bone but gain body fat. There is a need to quantify the magnitude of these changes in body composition because there are associated skeletal and cardiovascular health risks. We have compared total body and regional (lower limb) differences in body composition in a group of males with paraplegia and in healthy able-bodied males matched for age, and height using dual energy X-ray absorptiometry. Although patients and controls had similar body mass indices, significant reductions in lean tissue mass $(16 \%$ less) and bone $(12 \%$ less $)$ were observed in those with spinal cord injury. Group differences were even more pronounced in the lower limb. DEXA also revealed large increases in fat mass in subjects who did not look obese, total fat mass being $47 \%$ higher in the paraplegic group. We suggest that DEXA provides a simple and practical means to quantify both whole body and regional changes in body composition associated with spinal cord injury.
\end{abstract}

Keywords: paraplegia; body composition; DEXA; bone; fat; lean tissue mass

\section{Introduction}

A spinal cord injury is a devastating and lifethreatening event. Medical intervention aims to reduce the risks associated with traumatic damage to the spinal cord as soon as possible, and as a result, the life expectancy of a spinal cord injured patient today approximates that of an able-bodied person. ${ }^{1}$

However, immobilisation is associated with profound changes in the body composition in spinal cord injured (SCI) patients. ${ }^{2,3}$ There is loss of bone-free lean tissue mass (LTM) and bone, but gain in fat mass (FM), and these changes may be regional. The potential risks involved with these changes in body composition have implications for the health of the SCI individual. ${ }^{2-6}$ There is evidence that SCI patients are prone to coronary heart disease, non-insulin dependent diabetes mellitus (NIDDM) ${ }^{4,5,7,8}$ and bone fractures. $^{9-11}$ Thus there is a need to quantitate and monitor body composition changes accurately, in SCI individuals.

Various techniques have been used to assess the extent of changes in body composition in spinal cord injured. These include isotope-labelled water, ${ }^{12}$ total body potassium counting, ${ }_{13,14}^{13}$ anthropometric measures, ${ }^{15}$ hydrodensitometry, ${ }^{13,16}$ dual photon absorptiometry (DPA), ${ }^{14,17,18}$ and dual energy X-ray absorptiometry (DEXA). ${ }^{1-3}$ However, some of these methods are not particularly suitable for use in the SCI population. Hydrodensitometry is a difficult technique for people with restricted mobility and where the level

Correspondence: L Jones, School of Physical Education, University of Otago, PO Box 56, Dunedin, New Zealand of the cord lesion compromises respiratory muscle function, lung volume measurements are inaccurate. ${ }^{16}$ Anthropometric measures tend to underestimate fat per cent when compared with able bodied individuals. ${ }^{15}$ Equations necessary for the estimation of body composition from these two techniques are derived solely from able-bodied individuals and as such may not be the most appropriate for determining body composition in SCI.

In contrast, DEXA may provide a feasible and practical measure of body composition in SCI. It is safe, with a radiation dose below $5 \mathrm{mrem}$, and a whole body scan takes approximately $10-20 \mathrm{~min} .{ }^{19,20}$ This technique has been used in assessment of SCI and appears to be tolerated well by this population. ${ }^{1,2,21}$ DEXA provides a precise and accurate measure of body composition, and unlike chemical testing, hydrodensitometry or anthropometry, gives a regional distribution of bone, fat and lean tissue mass. ${ }^{19,22}$ The present short study was undertaken to examine bone and soft tissue changes, using DEXA, in a small group of male paraplegics in comparison with age- and height-matched able-bodied controls.

\section{Methods}

The study was approved by the ethics committee of the Southern Regional Health Authority. The patient group comprised five male paraplegics who had sustained their SCI for at least 1 year. Each was ageand height matched (within 5 years and $5 \mathrm{~cm}$, respectively) with two able-bodied male controls 
obtained from our local DEXA database $(n=10)$. Heights, weights and body mass index (BMI) calculated as weight $(\mathrm{kg})$ divided by height $\left(\mathrm{m}^{2}\right)$ were measured anthropometrically. Body composition was estimated by DEXA scanning as described previously. ${ }^{23}$ A total body scan (Lunar DPX-L, Software version $1.3 \mathrm{z}$, Madison, Wisconsin, USA) was performed on all subjects to determine total body and regional (legs) LTM, bone mineral content (BMC) and FM (kg). Bone mineral density (BMD) measurements $\left(\mathrm{g} / \mathrm{cm}^{2}\right)$ of the left hip (femoral neck, Wards triangle and trochanter) were also taken for the paraplegic group only; and LUNAR reference data have been used to show bone loss at this site.

Results are expressed as means $\pm \mathrm{SD}$. Independent $t$ tests (SPSS for Windows, 6.1) were used to detect significance between the groups. Statistical significance was set at 0.05 .

\section{Results}

Table 1 describes the mean values for age, weight, height, BMI, total body LTM, FM, fat percent and BMC of each group. Total body LTM, FM, per cent fat and BMC all differed significantly. The paraplegic group had $16 \%$ less total LTM than the control group, but carried $47 \%$ more total FM. Total BMC was $12 \%$ less in the paraplegic group.

Values of FM in the arms, trunk and head for the control group were $1.20 \pm 0.66 \mathrm{~kg}, 6.5 \pm 2.85 \mathrm{~kg}$ and $0.69 \pm 0.19 \mathrm{~kg}$. FM values for the paraplegic group

Table 1 Age, anthropometry and total body composition of paraplegic and control groups

\begin{tabular}{lcc}
\hline & $\begin{array}{c}\text { Paraplegic } \\
(\mathrm{n}=5)\end{array}$ & $\begin{array}{c}\text { Control } \\
(\mathrm{n}=10)\end{array}$ \\
\hline Age $(\mathrm{yrs})$ & $32.6 \pm 6.3$ & $29.9 \pm 5.2$ \\
Weight $(\mathrm{kg})$ & $76.2 \pm 18.8$ & $74.0 \pm 8.5$ \\
Height $(\mathrm{cm})$ & $175.0 \pm 5.0$ & $175.1 \pm 4.4$ \\
BMI $\left(\mathrm{kg} / \mathrm{m}^{2}\right)$ & $24.8 \pm 5.6$ & $24.1 \pm 2.5$ \\
Lean tissue mass $(\mathrm{kg})$ & $48.7 \pm 6.7^{* *}$ & $57.9 \pm 3.7$ \\
Fat mass $(\mathrm{kg})$ & $24.0 \pm 13.6^{*}$ & $12.6 \pm 4.9$ \\
Fat\% & $30.1 \pm 9.0^{* *}$ & $16.6 \pm 5.0$ \\
Bone mineral content $(\mathrm{kg})$ & $2.86 \pm 0.34^{*}$ & $3.3 \pm 0.26$ \\
\hline
\end{tabular}

Mean \pm SD. $* P<0.05, * * P<0.01$ were $2.08 \pm 1.28 \mathrm{~g}, 11.92 \pm 7.80 \mathrm{~kg}$ and $1.23 \pm 0.35 \mathrm{~kg}$ for the arms, trunk and head respectively. Control group results for $\mathrm{BMC}$ in the arms, trunk and head were $0.49 \pm 0.08 \mathrm{~kg}, 1.04 \pm 0.11 \mathrm{~kg}$ and $0.50 \pm 0.06 \mathrm{~kg}$. $\mathrm{BMC}$ for the paraplegic group were $0.49 \pm 0.09 \mathrm{~kg}$, $0.96 \pm 0.18 \mathrm{~kg}$ and $0.53 \pm 0.04 \mathrm{~kg}$ in the arms, trunk and head respectively. LTM showed little variation in the arms $7.12 \pm 1.31 \mathrm{~kg}$ vs $7.43 \pm 1.11 \mathrm{~kg}$, trunk $27.47 \pm 1.69 \mathrm{~kg}$ vs $25.35 \pm 3.10 \mathrm{~kg}$ and head $3.59 \pm 0.24 \mathrm{~kg}$ vs $3.22 \pm 0.45 \mathrm{~kg}$ in the control and paraplegic groups respectively.

Figures 1 and 2 illustrate the significant differences found between the groups for leg LTM, FM, and BMC, respectively. The paraplegic group leg LTM was $36 \%$ less than the controls, while the leg FM was $52 \%$ greater. Leg BMC was also compromised, with the paraplegic group having only $70 \%$ that of the control group.

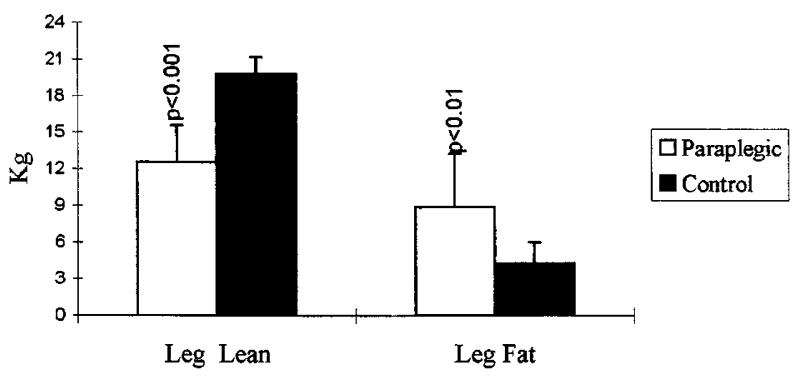

Figure 1 Regional lean and fat mass $(\mathrm{kg})$ for paraplegic and control groups (mean $\pm \mathrm{SD})$

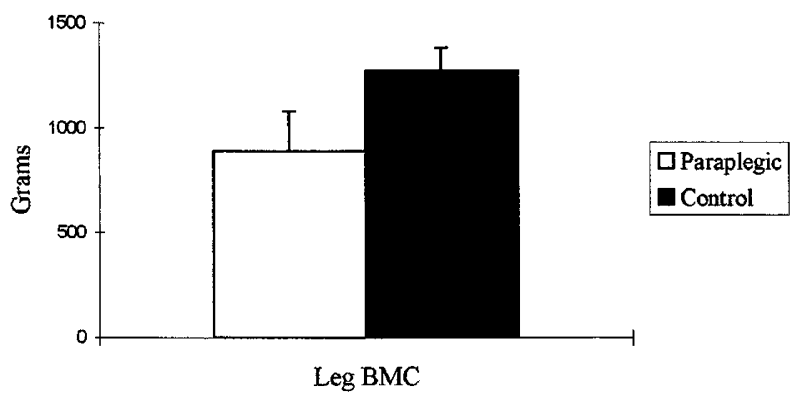

Figure 2 Regional bone mineral content (BMC) (grams) for paraplegic and control groups (mean \pm SD) $P<0.001$

Table 2 Details of level and duration of injury and hip regional bone mineral density in paraplegics. Z-scores (LUNAR database) shown in parentheses

\begin{tabular}{|c|c|c|c|c|c|}
\hline & \multirow[b]{2}{*}{ Level of injury } & \multirow{2}{*}{$\begin{array}{c}\text { Duration } \\
\text { of injury (years) }\end{array}$} & \multicolumn{3}{|c|}{ Bone mineral density $\left(\mathrm{g} / \mathrm{cm}^{2}\right)$} \\
\hline & & & Femoral neck & Wards triangle & Trochanter \\
\hline Subject 1 & $\mathrm{~T} 12-\mathrm{L} 1$ (I) & 1.33 & $0.589(-4.15)$ & $0.487(-3.89)$ & $0.437(-4.45)$ \\
\hline Subject 2 & $\mathrm{~L} 1-3(\mathrm{C})$ & 1.00 & $0.848(-1.32)$ & $0.697(-1.52)$ & $0.689(-1.63)$ \\
\hline Subject 3 & L1 (I) & 1.75 & $0.782(-1.97)$ & $0.743(-1.23)$ & $0.554(-3.02)$ \\
\hline Subject 4 & T12 (I) & 6.00 & $0.820(-2.43)$ & $0.792(-1.53)$ & $0.757(-2.09)$ \\
\hline Subject 5 & T5 (I) & 30.00 & $0.816(-1.78)$ & $0.693(-1.59)$ & $0.699(-1.96)$ \\
\hline
\end{tabular}

$\mathrm{I}=$ incomplete lesion, $\mathrm{C}=$ complete lesion 
Table 2 describes the lesion level and completeness, and duration of injury of the SCI with their hip densities. It also reports the age-matched BMD values $\left(\mathrm{g} / \mathrm{cm}^{2}\right.$ and $\mathrm{z}$-score) at the three regions of the left hip in the SCI individuals. Participants were $1.32-4.15$, $1.23-3.89$, and $1.63-4.45$ standard deviations below normative values (LUNAR) for age matched individuals at the femoral neck, Wards triangle and trochanter respectively.

\section{Discussion}

Our results illustrate marked differences in lean tissue mass, bone mass, and fat mass between paraplegic and healthy ambulant males with similar BMI. SCI patients had significantly less lean mass, lean bone mass but more body fat than their controls. Regional tissue compartments of the lower limbs were most affected. The magnitude of difference in body fat content was particularly striking, given the similarity of BMI and the normal physical appearance of the subjects. Paraplegics with a high fat content do not appear obese, presumably because lost lean tissue has been replaced by extra fat. The large increases in FM we observed were evident throughout the body and concur with the results of Wilmet et $a l^{3}$ (Hologic W2000) and Uebelhart et $a l^{2}$ (DPA). However, both these studies described repeated measures of SCI from the acute stage through to approximately $6-12$ months post injury in SCI patients, with subjects acting as their own controls. The patients in our study had been paraplegic for at least 1 year. In our study values for fat mass, both total body and regionally, were almost twice as great in SCI patients as in controls. This tendency for SCI to gain FM was also evident in the total body data and again coincide with Uebelhart et $a l^{2}$ Wilmet et $a l^{3}$ and Bauman et $a l^{5}$ (Lunar, DPX).

BMI values for our paraplegic group were similar to the controls and both groups were below the BMI considered to signify obesity $(\mathrm{BMI}>27.8){ }^{24}$ Yet from the DEXA measurements it can be seen that our paraplegic SCI were obese, with an average body fat percentage $>25 \%^{25}$ and because of this they may be at greater risk of developing CHD and/or diabetes. Increased incidences of these diseases are reported in SCI and are appearing in younger age groups. ${ }^{4,7}$

Lean tissue loss was also pronounced in the paraplegic group, in the lower limbs, with leg LTM being one third lower than the control group. The magnitude of leg and total LTM loss, we noted, was in agreement with that found in other studies. ${ }^{2,3,5}$ Loss of LTM may impact on the way in which insulin is managed within the body. An association between glucose intolerance and SCI, attributed to extreme inactivity and increased adiposity, has been reported and appears to coincide with the duration of the lesion. ${ }^{4,56}$ Post prandial glucose uptake is achieved primarily through the muscle mass, ${ }^{27}$ therefore it seems possible that loss of this tissue may contribute to the greater risk of developing diabetes in SCI. ${ }^{4,5}$
Total body BMC, in paraplegic patients, was $16 \%$ less than the control group and also fits with data obtained by others. ${ }^{2,3}$ In spinal cord injury, osteoporosis is thought to be a consequence of immobilisation and neurological deficit. ${ }^{18,28}$ Sublesional BMC loss is pronounced ${ }^{18}$ and our paraplegic group had retained only $70 \%$ of the leg BMC of the controls. Bone loss is considered to be greatest in the first 3-6 months following injury, stabilising at approximately $66 \%$ of the original, close to fracture threshold, between 12 and 16 months. ${ }^{18}$ Fractures may occur in SCI with insignificant provocation, and are attributed to large BMC losses., 11

Reductions in hip region BMD were large, with the average femoral neck BMD being $74 \%$ that of agematched controls (LUNAR database). BeDell et a ${ }^{29}$ (DEXA) found $79 \%$ BMD for the femoral neck in a group of paraplegics of similar duration of injury. This places our paraplegics in a high risk category for fracture. $^{30}$ One of our SCI patients had lost $45 \%$ of his BMD at the femoral neck and was also using orthosis-assisted walking as a rehabilitative tool. Although 'verticality' has had both physiological and psychological benefits in SCI, ${ }^{31,32}$ thought needs to be given to the BMD at an important weight-bearing site and its capability of sustaining the body weight.

Wards triangle (WT) and the greater trochanter (T) showed marked changes which were on average $75 \%$ and $68 \%$ respectively, below LUNAR norms. These figures are, again, slightly below those found by BeDell et $a l^{29} 82 \%$ (WT) and 71\% (T), and support the extent of bone loss at the hip associated with spinal cord injury.

In conclusion we have shown that DEXA can be used to quantitate body composition simply and accurately in SCI patients. It is particularly easy to underestimate the adiposity of these patients who have abnormally low lean tissue mass for a given body weight, but more fat. Implications for the magnitude of regional and total body changes in SCI illustrate the need to monitor these changes and institute a preventive program early in rehabilitation. While it appears that little can be done, at present, to prevent bone losses, specific dietary and exercise programmes could be used to preserve the lean tissue and to reduce fat accumulation. Our results indicate that DEXA appears to be the most practical method to date to assess body composition accurately and we suggest that it should be employed more widely in SCI patients.

\section{Acknowledgements}

We are grateful to the Burwood International Spinal Trust for the grant to support this work.

\section{References}

1 Szollar SM et al. Densitometric patterns of spinal cord injury associated bone loss. Spinal Cord 1997; 35: 374-382. 
2 Uebelhart D, Demiaux-Domenech B, Roth M, Chantraine A. Bone metabolism in spinal cord injured individuals and in others who have prolonged immobilisation. A review. Paraplegia 1995; 33: $669-673$.

3 Wilmet E et al. Longitudinal study of the bone mineral content and of soft tissue composition after spinal cord section. Paraplegia 1995; 33: 674-677.

4 Bauman WA, et al. Coronary artery disease: Metabolic risk factors and latent disease in individuals with paraplegia. Mt Sinai $J$ Med 1992; 59: $163-168$.

5 Bauman WA, Spungen AM. Disorders of carbohydrate and lipid metabolism in veterans with paraplegia or quadriplegia: A model of premature aging. Metabolism 1994; 43: 749-756.

6 Bjorntorp P. The associations between obesity, adipose tissue distribution and disease. Acta Med Scandin 1988; 723: 121 - 134.

7 Kocina P. Body composition of spinal cord injured adults [Review]. Sports Medicine 1997; 23: 48-60.

8 DeVivo MJ, Black KJ, Stover SL. Causes of death during the first 12 years after spinal cord injury. Arch Phys Med Rehabil 1993; 74: $248-254$.

9 Comarr AE, Hutchinson RH, Bors E. Extremity fractures of patients with spinal cord injuries. Am J Surg 1962; 103: 732 - 739.

10 Ragnarsson KT, Sell GH. Lower extremity fractures after spinal cord injury: a retrospective study. Arch Phys Med Rehabil 1981; 62: $418-423$.

11 Freehafer AA. Limb fractures in patients with spinal cord injury. Arch Phys Med Rehabil 1995; 76: 823 - 827.

12 Nuhlicek DN et al. Body composition of patients with spinal cord injury. Eur J Clin Nut 1988; 42: $765-773$.

13 Lussier L et al. Body composition in two elite female wheelchair athletes. Paraplegia 1983; 23: $16-22$.

14 Spungen AM, Bauman WA, Wang J, Pierson RN. Reduced quality of fat free mass in paraplegia. Clinical Research 1992; 40: 280A.

15 Bulbulian R, Johnson RE, Gruber JJ, Darabos B. Body composition in paraplegic male athletes. Med Sci Sport Exer 1987; 19: $195-201$.

16 Sedlock DA, Laventure SJ. Body composition and resting energy expenditure in long term spinal cord injury. Paraplegia 1990; 28: $448-454$.

17 Changlai SP, Kao CH. Bone mineral density in patients with spinal cord injury. Nucl Med Comm 1996; 17: 385-388.

18 Garland DE et al. Osteoporosis after spinal cord injury. J Orthop Res 1992; 10: $371-378$.
19 Mazess RB, Barden HS, Bisek JP, Hanson J. Dual-energy X-ray absorptiometry for total-body and regional bone-mineral and soft-tissue composition. Am J Clin Nut 1990; 51: 1106-1112.

20 Roubenoff R, Kehayias JJ, Dawson-Hughes B, Heymsfield SB. Use of dual-energy X-ray absorptiometry in body-composition studies: not yet a gold standard. Am J Clin Nut 1993; 58: 589591.

21 Chow YW et al. Ultrasound bone densitometry and dual energy $\mathrm{X}$-ray absorptiometry in patients with spinal cord injury: a crosssectional study. Spinal Cord 1996; 34: 736-741.

22 Wahner HW, Fogelman I. The evaluation of osteoporosis: Dual energy X-ray absorptiometry in clinical practice. London: Martin Dunitz Ltd; 1994.

23 Goulding A et al. Changing femoral geometry in growing girls. A cross-sectional DEXA study. Bone 1996; 19: 645-649.

24 National Institutes of Health Consensus Development Panel Conference Statement: Health implications of obesity. Ann Intern Med 1985; 103: $1073-1077$.

25 Lohman TG. Advances in body composition assessment. In: Current Issues in Exercise Science Series, Monograph No. 3. Champaign, Illinois: Human Kinetics Publishers; 1992.

26 Duckworth WC et al. Glucose intolerance due to insulin resistance in patients with spinal cord injuries. Diabetes 1980; 29: $906-910$.

27 DeFronzo RA et al. The effect of insulin on the disposal of intravenous glucose. Results from indirect calorimetry and hepatic and femoral venous catheterisation. Diabetes 1981; 30: $1000-1007$.

28 Hill EL et al. Changes in bone in a model of spinal cord injury. $J$ Orthop Res 1993; 11: 537-547.

29 BeDell KK, Scremin AME, Perell KL, Kunkel CF. Effects of functional electrical stimulation-induced lower-extremity cycling on bone-density of spinal cord-injured patients. Amer J Phys Med Rehabil 1996; 75: 29-34.

30 Eisenberg B et al. Factors affecting bone mineral density in elderly men receiving chronic in-center dialysis. Clin $\mathrm{Nucl} \mathrm{Med}$ 1991; 16: $30-36$.

31 Bohannon RW. Tilt table standing for reducing spasticity after spinal cord injury. Arch Phys Med Rehabil 1993; 74: $1121-1122$.

32 Gallien $\mathrm{P}$, et al. Restoration of gait by functional electrical stimulation for spinal cord injured patients. Paraplegia 1995; 33: $660-664$. 